\title{
Depression and alexithymia on weight perception in patients with metabolic syndrome and type 2 diabetes
}

\author{
Maria Cristina de Oliveira Regina ${ }^{1^{*}}$ (I) and Marcos Antonio Tambascia ${ }^{2}$
}

\begin{abstract}
Background: Obesity's increasing follows decreased perception of weight status in obese persons, mainly female, undergoing age-related changes.

Objective: To study weight perception and psychological alterations associated to MS and T2DM.

Methods: 200 patients selected from Metabolic Syndrome Outpatient Clinic of University of Campinas. Instruments: Beck Depression and Beck Anxiety Inventories', Toronto Alexithymia Scale-26s, questionnaire and data from reports. Approved by Unicamp Research Ethic Committee.

Results: Patients aged 18-40 years perceived their weight higher than actual $(A<D)(p=0.0272)$, amongst untreated hypertensive $(p=0.037) . \geq 41$ years old patient's subdivided into $A=D$ and $A>D . A=D$ had 4.3 more chances to be alexithymic than $A<D$. 35\% of $A<D$ accepted their physical appearance, contrarily $A=D(66 \%)$ and $A>D(69 \%)(p=0.0018)$. 50\% of $A<D$ felt offended by social aggression due to their weight; $A=D(20 \%)$ and $A>D$ (34\%) $(p=0.007)$. 3.6 more chances of $A>D$ than $A<D$ using anti-hypertensive drugs $(p=0.021)$ ( $\geq 41$ years old) and 3.5 more chances to perceive $A=D(41-60$ years old $)(p=0.023)$. $A=D$ presented 3.8 more chances of depression than $A<D$ and 4.3 more chances of alexithymia than $A<D$ (62\% of $41-60$ year-old patients with higher cholesterol, mainly $L D L$ and hyper-triglycerides). $A=D$ with alexithymia, partially linked with higher cholesterol, suggests neuroinflammation due to hypertriglycerides. Females, who declared had been anteriorly made diet as treatment to lose weight were exactly those who perceived their weight A > D (45\%, $p=0.0091)$.
\end{abstract}

Conclusions: Age as a period of development, in which cultural influences occurs, was a factor in weight misperception. $A<D$ and $A>D$ were distinct in age, history of obesity and BMI.

Keywords: Perception of weight, Actual body mass index, Reported or declared body mass index, Dyslipidemia, Hypertension, Type 2 diabetes mellitus, Alexithymia, Depression, Anxiety and psychological aspects

\section{Background}

Evidence supports that increasing prevalence of obesity has been accompanied by decreasing perception of weight status in obese people [1]. Female were likelier than male, to consider themselves as overweight across each BMI category, and more attempted to lose weight. Both males and females with higher BMI were associated

\footnotetext{
*Correspondence: cdregina@mpc.com.br; cdregina@fcm.unicamp.br ${ }^{1}$ Department of Human Being Development and Rehabilitation, Medical Faculty of State University of Campinas, Campinas, Brazil

Full list of author information is available at the end of the article
}

with lower chance of trying to lose weight than patients slightly overweight [1]. Process of aging can affect female body image perception. Female with body image dissatisfaction, or who perceived themselves as "unattractive" had higher inaccuracy regarding perception of their bodies [2]. Middle-aged women with poor body image are more likely to have clinically significant levels of symptoms of depression [2]. As obesity has increased in the United States [3], studies have found that Americans' perception of their own weight has not often aligned with their actual BMI. The accuracy of weight perception was associated with gender, race, and education level in 
a study regarding dissatisfaction among adolescents in 24 countries [4]. Body weight dissatisfaction was highly prevalent and more common in girls than boys were, if overweight than non-overweight adolescents and if older than young.

The number of type 2 diabetes mellitus (T2DM) is increasing in every country, especially in those with low and middle-income. T2DM has often found between ages 40-59 [5].

Metabolic syndrome (MetS) is a cluster of cardiometabolic risk factors that includes obesity, insulin resistance, dyslipidemia and hypertension [6, 7]. MetS has been considered a pre-diabetes state [8]. It can be caused by genetic associations [9] and other factors as obesity, medications for anxiety, depression, psychoses, HIV, allergies, respiratory diseases and frequent exposure to high levels of cortisol in prolonged stress [10]. Visceral obesity is a relevant factor [10]. The MetS has been recognized by the WHO and other important institutions such as: The National Cholesterol Education Program (NCEP), and The Adults Treatment Panel III (APTIII) [11].

Obesity, as important factor in MetS, increases the incidence to T2DM. Other factors as family history of diabetes, unhealthy or obesogenic diet, physical inactivity, increasing age, high blood pressure, ethnicity, impaired glucose tolerance, history of gestational diabetes and poor nutrition during pregnancy [5] can contribute to cause MetS.

A decline in complications has been associated with T2DM, but not in rates of amputation, stroke or endstage of renal disease [12]. People who developed T2DM had presented increased glucose values and reduced insulin sensitivity 13 years before the diagnosis [8].

Aging is associated with increasing of total body weight and visceral adiposity [12]. Despite BMI continues stable, percentage of fat tissue is higher with age [13] and visceral adiposity linked to MetS. Prevention and weight control, in MetS patients, mainly in patients with T2DM, is very important due to the damages caused by the continuous state of pro-inflammation [6]. Overweight perception is a source to conduct patients to control those damages.

Alexithymia is the difficulty in identifying and describing feelings [14], an alteration on emotional regulation [15]. It represents a deficit in cognitive processing of affection, which predisposes to several physical and psychiatric illnesses. Neurologically, the physiological motor expressive area is active, more than cognitive experiential domain of the system of emotional response [16]. It has especially been linked with psychiatric and psychosomatic disorders [16] such as somatization [14], depression and anxiety [17-21]. Alexithymia is elevated in people with both eating and drug-related disorders
[22]. They have link with compulsive behavior disorders. It is described as the difficulty of identifying feelings in other people too, including main basic feelings $[17,23-32]$. Studies regarding alexithymia have shown that patients with alexithymia present hypersensitivity to bodily sensations due to neural features, which are activated more on physiologic or motor expressive levels than on cognitive-domains of the emotional response system [32].

Depression-related biological alterations in the hypothalamic-pituitary-adrenal cortex axis, occurs due to subclinical inflammation or as resultant of the sympathetic nervous system, were not relevantly linked to increased risk of diabetes [33-36]. A modestly bidirectional association between T2DM and depression [37] was found in a meta-analyses of cohort studies. Other studies showed no conclusive bidirectional influence between them [38].

Some studies pointed out the association of depression with pro-inflammatory markers or inflammatory states, demonstrating a link to immunological activity. Some of those inflammatory markers are the same found in obese states $[35,36]$.

Diabetes, as well as other chronic disorders, increases the risk of depression in equal dimension. The possibility of a faster cognitive decline due to T2DM exists as long as related to duration of the disease and to the glycemic control [37]. It was observed [39] that the brain, under higher BMI, is related to Alzheimer's disease [39].

Few studies have been conducted regarding perception of obesity, MetS and alexithymia, mainly focusing on depression and anxiety, and showing types of weight perception. Probably because of pro-inflammatory state, it is possible that obesity has a link with alexithymia. Alteration of perception in general can be affected by this factor. The eventual relationship between MetS and Alexithymia may probably be demonstrated. Certain health parameters that compound MetS can have association with both alexithymia and weight perception alterations. If the weight perception is affected, it is possible to establish tendencies considering the levels of obesity; and to establish the levels of alexithymia, mainly if alexithymia is, secondarily, linked to depression and/or anxiety. Demographic items, such as age and gender may also affect those associations.

\section{Methods}

Sample: 200 patients was, randomly, selected from 800 patients attended per year, in Metabolic Syndrome Outpatient Clinic of the State University of Campinas (Brazil); they accepted to participate in the study using the Free and Informed Consented Form. Twenty of them were excluded because they did not adequately complete one or more of 
the tests or the questionnaire; 10 were also excluded due to diseases which could be confounding factors. The Research Ethics Committee of the University of Campinas approved the study. The participants ranged from 18 to 71 years, both genders. It is a cross-sectional study. Instruments: a questionnaire with closed questions (socio-demographic items, attitudes and psychological aspects related to obesity), Beck Depression Inventory, Beck Anxiety Inventory and Toronto Alexithymia Scale-26 and data from reports concerning control of metabolic disorder. Diagnosis of type 2 diabetes mellitus was considered if fasting plasma glucose was higher than $126 \mathrm{mg} / \mathrm{dl}$; or if there was use of medication for them. Classification of obesity was based on body mass index that is calculated by the formula: weight/height 2 and considered as follows: between 25 and 30 as overweight, 30 and 35 as obesity grade I, 35 and 40 as obesity grade II and more than 40 as severe obesity or grade III. Statistics: Fisher test to study the prevalence and Chi Square for correlations among variables and study of prevalence; Multiple Linear Regression and Multiple Correspondence Factor Analyses in order to analyze co-variance and the chance that they happen together.

\section{Results}

\section{Demographic aspects}

Weight perception presented a differential between 18 and 40 years old patients: actual BMI > declared BMI $(\mathrm{A}>\mathrm{D})(18 \%)$ and Actual BMI < declared BMI $(\mathrm{A}<\mathrm{D})$ (39\%). Married was prevalent amongst patients who perceived their weight $\mathrm{A}>\mathrm{D}$; $\mathrm{A}<\mathrm{D}$ amongst unmarried was prevalent among $\mathrm{A}<\mathrm{D}$ patients (see Table 1). Formal education was not significant in all types of weight perception.

In male gender there was particularities to incorrectly perceive weight (BMI): $\mathrm{A}>\mathrm{D}=35 \%$ and $\mathrm{A}<\mathrm{D}=15 \%$. In $\mathrm{A}<\mathrm{D}$, females were prevalent: fewer male patients perceiving their weight $\mathrm{A}<\mathrm{D}$. According to multiple correspondence analyses test, male patients presented certain features (55\%): they did not make any treatments for weight loss, were $\geq$ BMI III; they disapproved their own physical appearance (possibly they were not able to transform their non-acceptance into actions to ameliorate appearance), did not feel upset due to their disease (denying mechanism), diet or medical treatment. They also declared not having difficulty to expose their sentiments, however had alexithymia and severe or moderate depression and anxiety.

\section{Hypertension, dyslipidemia and weight perception}

Hypertension could result of (or from) hyperinsulinemia induced by obesity and/or T2DM and other factors. Systolic pressure were different between patients aged $\leq 40$ years old (higher) and $41-60$ years old (lower); and $\geq 61$ years old (higher) (0.026). Literature evaluates differently the ideal level of systolic blood pressure, considering age. [39, 40]. Higher diastolic pressure was in aged $\leq 40$ years old. Hypertension, prevalent in $\leq 40$ years old, possibly was initial effect of lesser sensibility of insulin and inadequate eating habits; in patients aged $\geq 61$ years old, probably was result of a longer history of obesity and worse management of insulin prescribed.

$\mathrm{A}<\mathrm{D}$ was present in hypertension without use of antihypertensive, in patients with $\leq 40$ years old; while use of anti-hypertensive was linked with $\mathrm{A}>\mathrm{D}$ or $\mathrm{A}=\mathrm{D}$. It means that anti-hypertensive did not influence weight perceptions in $\mathrm{A}=\mathrm{D}$. Some factor associated to hypertension can be linked with $\mathrm{A}>\mathrm{D}$.

Patients who were not making use of anti-hypertensive drugs and perceived their weight $\mathrm{A}<\mathrm{D}$ were statistically significant (see Table 1). Patients using anti-hypertensive presented 3.6 more chances of $\mathrm{A}>\mathrm{D}$ than $\mathrm{A}<\mathrm{D}$ or 3.5 more chances to perceive $\mathrm{A}=\mathrm{D}$ than $\mathrm{A}<\mathrm{D}$. It was not studied how frequently and correctly anti-hypertensive drug were used by them or how accessible for patients it was. In $\mathrm{A}=\mathrm{D}$ the use of anti-hypertensive did not affect weight perception. Then A > D could be more affected by anti-hypertensive probably due to wrong way to use it, even though correct prescription and orientation.

In patients who perceived A > D: $46 \%$ were not previously submitted to diet to lose weight ( $p=0.0091)$, which is in agreement with literature. It was observed in male gender in multiple correspondence analysis test. The lack of diet could have contributed to less results, suggesting worse posture toward own health. If irregular access of antihypertensives, or uncorrected use by patients, the hypertension could not be controlled.

Non-treated hypertension suggests that alexithymia could be secondary to hypertension, explaining partially the misperception in this age interval $(\leq 40)$. Depression and use of anti-hypertensive among $\mathrm{A}=\mathrm{D}$ did not seem to interfere in weight perceiving. It might express levels of pro-inflammatory state. Depression itself can represent psychological elaboration of the own health state. The dimension of weight misperception in male who presented alexithymia, severe or moderate depression, and/or anxiety, was relevant in $\mathrm{A}>\mathrm{D}$, despite also present in female. Age and level of BMI (higher) seems linked with them.

$\mathrm{A}=\mathrm{D}$ presented higher LDL (133 $\mathrm{mg} / \mathrm{dl}), \mathrm{A}>\mathrm{D}$ higher total cholesterol $(205 \mathrm{mg} / \mathrm{dl})$ and hypertriglycerides (323 mg/dl). Neuro-inflammation could be linked with A > D.

\section{History of obesity, body mass index and weight perceptions}

$18 \%$ declared obesity during infancy in $\mathrm{A}=\mathrm{D}$, but $33 \%$ in $\mathrm{A}>\mathrm{D}$ and $40 \%$ in $\mathrm{A}<\mathrm{D}$ too; and obesity 
Table 1 Differences between actual body mass index (A) - declared body mass index (D)

\begin{tabular}{|c|c|c|c|c|c|}
\hline & $A=D$ & $A>D$ & $A<D$ & Total & $p$ value \\
\hline Gender & & & & & 0.0874 \\
\hline Female & $39(74 \%)$ & $36(65 \%)$ & $39(85 \%)$ & 114 (74\%) & \\
\hline Male & $14(26 \%)$ & $19(35 \%)$ & $7(15 \%)$ & $40(26 \%)$ & \\
\hline Total & $53(34 \%)$ & $55(36 \%)$ & $46(30 \%)$ & 154 (100\%) & \\
\hline Civil state & & & & & 0.0657 \\
\hline Married & $30(57 \%)$ & $40(73 \%)$ & $23(51 \%)$ & 93 (61\%) & \\
\hline Not married & $23(43 \%)$ & $15(27 \%)$ & $22(49 \%)$ & $60(39 \%)$ & \\
\hline Total & $53(35 \%)$ & $55(36 \%)$ & 45 (29\%) & $153(100 \%)$ & \\
\hline Age intervals & & & & & 0.0272 \\
\hline 18-40 years old & $12(23 \%)$ & $10(18 \%)$ & $18(39 \%)$ & 40 (26. \%) & \\
\hline $41-60$ years old & $32(62 \%)$ & $34(62 \%)$ & 27 (59\%) & $93(61 \%)$ & \\
\hline$\geq 61$ years old & $8(16 \%)$ & $11(20 \%)$ & $1(2 \%)$ & $20(13 \%)$ & \\
\hline Total & $52(34 \%)$ & $55(36 \%)$ & $46(30 \%)$ & $153(100 \%)$ & \\
\hline Anti-hypertensive & & & & & 0.0372 \\
\hline No & 37 (70\%) & 39 (69.6\%) & 41 (89\%) & $117(75 \%)$ & \\
\hline Yes & $16(30 \%)$ & $17(30 \%)$ & $5(11 \%)$ & $38(24.5 \%)$ & \\
\hline $\begin{array}{l}A>D \times A<D \text { (with anti-hypertensive) } \\
A=D\end{array}$ & $\begin{array}{l}\text { odds ratio }=3.574 \\
\text { odds ratio }=3.546\end{array}$ & & $\begin{array}{l}p=0.0219 \\
p=0.0239\end{array}$ & & \\
\hline Anti-depression & & & & & 0.3246 \\
\hline No & $47(89 \%)$ & $47(84 \%)$ & $43(93 \%)$ & $137(88 \%)$ & \\
\hline Yes & $6(11 \%)$ & $9(16 \%)$ & $3(7 \%)$ & $18(12 \%)$ & \\
\hline \multicolumn{6}{|l|}{ Body mass index } \\
\hline 1 & $6(21.4 \%)$ & $0(0.0 \%)$ & $22(78.6 \%)$ & $28(100 \%)$ & $<0.0001$ \\
\hline$\|$ & $28(41.2 \%)$ & $16(23.5 \%)$ & $24(35.3 \%)$ & $68(100 \%)$ & \\
\hline III & $0(0.0 \%)$ & $40(67.8 \%)$ & $19(32.2 \%)$ & $59(100 \%)$ & \\
\hline Beck depression inventory & & & & & 0.0499 \\
\hline Low level & $33(70 \%)$ & $36(71 \%)$ & $36(90 \%)$ & $105(76 \%)$ & \\
\hline Moderate/severe & $14(30 \%)$ & $15(29 \%)$ & $4(10 \%)$ & $33(24 \%)$ & \\
\hline Total & 47 & 51 & 40 & $138(100 \%)$ & \\
\hline Moderate or severe depression & $\begin{array}{l}A>D \times A<D \\
A=D \times A<D\end{array}$ & $\begin{array}{l}p=0.0337 \\
p=0.0297\end{array}$ & & $\begin{array}{l}\text { odds ratio }=3.648 \\
\text { odds ratio }=3.817\end{array}$ & \\
\hline Toronto Alexithymia Scale-26 & & & & & 0.0161 (Fisher) \\
\hline No & $1(2 \%)$ & $2(4 \%)$ & $6(16 \%)$ & $9(7 \%)$ & \\
\hline Probable alexithymia & $8(17 \%)$ & $13(25 \%)$ & 13(34\%) & $34(25 \%)$ & \\
\hline Alexithymia & $39(81 \%)$ & $37(71 \%)$ & $19(50 \%)$ & $95(69 \%)$ & \\
\hline Total & 48 & 52 & 38 & $138(100 \%)$ & \\
\hline Alexithymia/BMI actual × BMI declared & $\begin{array}{l}A>D \times A<D \\
A=D \times A<D\end{array}$ & $\begin{array}{l}p=0.0368 \\
p=0.0029\end{array}$ & $\begin{array}{l}\text { odds ratio }=2.533 \\
\text { odds ratio }=4.333\end{array}$ & & \\
\hline
\end{tabular}

${ }^{a}$ Anxiety measured by Beck Anxiety Inventory did not present statical significance according to Chi square test: $p=0.1497$; it was observed only the following difference, comparing on their actual BMI and their declared BMI (A < D): minimal level of anxiety $68 \%$ and moderate or high level of anxiety $32 \%$

${ }^{b}$ Prevalence of probable alexithymia (38\%) was among patients who did not use anti-hypertensive medication and did not have controlled hypertension. Prevalence (86\%) of alexithymia among patients with controlled hypertension and used anti-hypertensive medication $(p=0.069)$

during adolescence: $33 \%, 52 \%$ and $48 \%$ respectively. $90 \%$ of $\mathrm{A}=\mathrm{D}$ declared obesity in adulthood, more than $\mathrm{A}>\mathrm{D}$ (73\%). Obesity in $\mathrm{A}=\mathrm{D}$ seems later acquired, in middleage, than in $\mathrm{A}>\mathrm{D}$ and $\mathrm{A}<\mathrm{D}$.

Differences statically significant $(\mathrm{p} \leq 0.0001)$ were in types of weight perception considering levels of actual
BMI: A < D prevalent in $79 \%$ of patients with BMII I and $\mathrm{A}>\mathrm{D}$ in $68 \%$ of BMI III.

A $>$ D could result of structural brain alteration in perception area, designed or not by cultural body size pattern. Such alteration seems opposite to misperception in anorexic patients: A > D patients probably did not 
perceive promptly their gain of weight, alterations in body size, despite changing due to plus weight. If linked with BMI III could be deleterious effect in brain, possibly related to difficulties in recognizing satiety such as compulsive behavior.

$\mathrm{A}=\mathrm{D}$, without weight perception alterations, was prevalent in BMI II. A $<$ D associated to BMI I, seems a misperception did no related to structural brain alterations. Probably A $<$ D, influenced by hypertension non treated, can suffer any temporary damage in such area.

\section{Psychological aspects and types of weight perception}

Higher levels of depression were prevalent in patients who perceived $\mathrm{A}=\mathrm{D}$ and $\mathrm{A}>\mathrm{D}$. Minimal levels of depression were prevalent in patients $A<D(p=0.049)$. Depression in both cases $(\mathrm{A}=\mathrm{D}$ and $\mathrm{A}>\mathrm{D})$ can result of pro-inflammatory state of those patients, stressor events in their lives, or their awareness regarding their poor health. Since BMI I (minimal levels), but clearly $\geq$ BMI II, pro-inflammatory signs seems producing effects as depression.

$35 \%$ of $\mathrm{A}<\mathrm{D}$ accepted their physical appearance, contrarily of $\mathrm{A}=\mathrm{D}(66 \%)$ and $\mathrm{A}>\mathrm{D}(69 \%)(\mathrm{p}=0.0018) . \mathrm{A}<\mathrm{D}$ seems genuinely a perception alteration, probably not as a result of a self-censure. $50 \%$ of $A<D$ felt offended by social aggression about their weight; $\mathrm{A}=\mathrm{D}(20 \%)$ and $\mathrm{A}>\mathrm{D}$ $(34 \%)(p=0.007)$. The elevated percentage of patients who feeling target of social aggression in $\mathrm{A}<\mathrm{D}$, compared with the acceptation of their own appearance, could signalize denying (psychological mechanism): the censure remained "outside", but denied by themselves. $69 \%$ of A $<$ D was unsatisfied with themselves due to their disease (48\% of $A=D ; 42 \%$ of $A>D)(p=0.027)$. As they were predominately BMI I and youngest, being portable of a disease could seem to them less acceptable. $74 \%$ of $\mathrm{A}<\mathrm{D}$ felt unsatisfied with themselves because their obesity; A = D (51\%) and $\mathrm{A}>\mathrm{D}(54 \%)(\mathrm{p}=0.068)$. Despite $\mathrm{A}<\mathrm{D}$ expressing highly unsatisfied with these items they were less affected by depression. The lesser was their dissatisfaction, in patients who presented $A=D$ or $A>D$, the greater was their depression: as $\mathrm{A}=\mathrm{D}$ could be psychological elaboration, but A > D probably linked with culpability, or damage in weight perception due to neuro-inflammation. Higher BMI and age, likely lesser the faith to achieve better results due to aging. Crescent the BMI, higher could be the conformism and lower the feeling to be able to fight against of obesity's growing. A > D could be affected by emotional eating. They felt dissatisfaction with their obesity, more than $\mathrm{A}=\mathrm{D}$ whose obesity seems recent than in $\mathrm{A}>\mathrm{D}$. BMI III if earlier linked with emotional eating, could after be intensified by cited brain damage.

A $>$ D associated with BMI III, seems higher affected by pro-inflammatory effects. A $>$ D linked with depression,
BMI III and use of anti-hypertensive could be associated to irregular behavior regarding health, mainly males, who did not make diet, physical activity and treatments. If BMI III patients were greater emotionally immature their adherence to health habits could be compromised.

$\mathrm{A}=\mathrm{D}$ was associated with BMI II and presented depression-related. This depression could be less associated with culpability, considering the accurate weight perception evolved. It can be related to a psychological elaboration process regarding their awareness of BMI, difficulties related to treatment, diet, aging and others aspects. It seems related to their health state and effect of their pro-inflammatory process which could reinforce levels of depression. Other sources of stress were not studied to explain prevalence of depression in BMI II. However, among female, climacteric and menopause can be linked with. They also used anti-hypertensive medication. It did not interfere in their weight perception. These patients could have regular attitude regarding the anti-hypertensive medication, following correctly instructions.

Patients who perceived A > D exhibited 3.6 more chances to present moderate or severe depression than $\mathrm{A}<\mathrm{D}$. $\mathrm{A}=\mathrm{D}$ demonstrated 3.8 more chances to present moderate or severe depression than $\mathrm{A}<\mathrm{D}$. It is possible that in $\mathrm{A}=\mathrm{D}$, middle-age with their hormonal alterations, mainly amongst female, and initial stage of treatment's against obesity due to recent acquisition of obesity, elevated the chances of depression-related to pro-inflammation. Gain of weight in middle-age could be culturally tolerated due to expectations about aging.

The higher the BMI, A $>$ D was the prevalent type of perception. The lesser the $\mathrm{BMI}, \mathrm{A}<\mathrm{D}$ was the type; intermediate BMI, A $=$ D. Despite A $>$ D could be a type of perception reflecting structural brain alterations, it seems that pro-inflammation and depression-related were strongest associated to $\mathrm{A}>\mathrm{D}$ such as bias in perceiving weight, reinforcing it as vicious circle. $\mathrm{A}<\mathrm{D}$, if not enough affected by pro-inflammation, presented a minimal depression. Since middle-age, and among BMI II and BMI III patients, depression was present in similar level.

Probable alexithymic patients were prevalent among $\mathrm{A}<\mathrm{D}$ as a frontier (34\%). It was present among in $\mathrm{A}>\mathrm{D}$ (29\%) and A = D (17\%). Probable alexithymia and minimal levels of depression could be, beside non controlled hypertension, symptom of initial damages caused by obesity. The higher was the obesity expressed by BMI, the lesser was the presence of probable alexithymia. The distribution of probable alexithymia was opposite to the way to perceive weight: A $<\mathrm{D}(34 \%)$ and $\mathrm{A}>\mathrm{D}(29 \%)$.

$\mathrm{A}<\mathrm{D}$, due to interval of age, could result of more rigorous expectations to deal with obesity and weight control, suggesting intern demand induced by external cues. 
A > D likely express, despite probable irregular use of anti-hypertensive and failed access to this medication, unstable attitude regarding treatment. A > D showed lesser patients earlier evolved in diet, during life, than $\mathrm{A}<\mathrm{D}$ and $\mathrm{A}=\mathrm{D}(\mathrm{p}=0.0091)$. It suggests worse attitude regarding eating, health and weight, lesser motivation or more negligence with health-items.

Patients who perceived their weight as $\mathrm{A}<\mathrm{D}$ prevalently showed lower level of depression and less alexithymia (50\%) compared with $\mathrm{A}>\mathrm{D}$ and $\mathrm{A}=\mathrm{D}$ (see Table 1 ). In $\mathrm{A}>\mathrm{D}$, alexithymia seems secondarily associated with depression.

Alexithymia, associated to BMI III and depression, seems susceptible to influences of brain alterations (amygdala, cingular gyrus and linked areas) already present. Imprecise perception of patients regarding items in general, including obesity, and different reaction in dealing with visual food stimulation can be linked with. Cognitive damages due to aging, low level of formal education and lack of information to behave correctly toward health, could still be associated.

Congruently the "pure" alexithymic (did not linked with depression or anxiety or both) was prevalent between $\mathrm{A}<\mathrm{D}$ weight perception (43\%). The Alexithymia associated with depression and/or anxiety was prevalent in those who perceived the weight A > D (22\%). (see Table 1). The disapproval of their own appearance was present in those who perceived their weight as A > D $(\mathrm{p}=0.0018)$ (a feature in male subjects). There was 2.5 more chances of alexithymia in $\mathrm{A}>\mathrm{D}$ than $\mathrm{A}<\mathrm{D}$. Alexithymia was specially related to $\mathrm{A}>\mathrm{D}$, but $\mathrm{A}>\mathrm{D}$ was strongly related to depression, mainly among BMI III. Their misperception is accompanied by lesser comprehension of their own feelings; part of them disapproved their appearance. If they did not be able to control factors as weight, it can signalize less adherence to treatments, which was indicated by males.

In $\mathrm{A}<\mathrm{D}$, the influence of depression was minimal, and the influence of alexithymia was lower than among other types of weight perception, if aged $\leq 40$ years old. BMI I was prevalent between $\mathrm{A}<\mathrm{D}$. $\mathrm{A}<\mathrm{D}$ was associated to hypertension, not treated by anti-hypertensive $(\mathrm{p}=0.037)$. Alexithymia, if present amongst them, seems to be "pure" alexithymia (not associated with depression and anxiety). Whether there was less expressive effects of pro-inflammation, in $\mathrm{A}<\mathrm{D}$ proinflammation, eventually neuro-inflammation, seems more relevant for alexithymia than depression.

Being $\leq 40$ years old patients seems more relevant, beside civil state in lower level, reflecting developmental and cultural period of influence, with specific exigencies as: being "attractive" to achieve a partner, to obtain a stable profession and an occupational performance. If married the partner perception of weight can influencing self-image. Amongst non-married more stress, more lack of confidence in themselves and less skills to establish significant attachment could be evolved.

In $\mathrm{A}=\mathrm{D}$ the differences in presence of obesity during infancy, adolescence and adulthood were more distinct: 6,11 and $31 \%$ respectively. The differences of obesity at each period of development was less distinguishable in $\mathrm{A}>\mathrm{D}(11,18$ and $25 \%)$, and in $\mathrm{A}<\mathrm{D}(13,15$ and $27 \%)$. In $\mathrm{A}=\mathrm{D}$ the presence of obesity since adulthood is higher than in other period of life-course. In $\mathrm{A}>\mathrm{D}$ and $\mathrm{A}<\mathrm{D}$ it was not greatly the difference between them in each period. $\mathrm{A}=\mathrm{D}$ indicated less presence of obesity during infancy, while $\mathrm{A}>\mathrm{D}$ and $\mathrm{A}<\mathrm{D}$ were similar at this point.

In summary, 3 types of weight perception present distinguishable differences: $\mathrm{A}>\mathrm{D}, \mathrm{A}=\mathrm{D}$ and $\mathrm{A}<\mathrm{D}$. $\mathrm{A}<\mathrm{D}$ seems related to better self-control (BMI I) despite presence of obesity during infancy and adolescence. A > D seems reflecting lesser self controlled patients, with lesser diet during infancy and adolescence: possibly lack of model to better control their eating habits or lack of limits on food intake along life. $\mathrm{A}=\mathrm{D}$ presented as main features: 3.8 more chances of depression than $\mathrm{A}<\mathrm{D}$ (unhealthy state, beginning of treatment, probable elaboration of their disease and psychological state) and 4.3 more chances of alexithymia than $\mathrm{A}<\mathrm{D}(62 \%$ of 41-60 year-old patients; many presented higher cholesterol, mainly LDL and hypertriglycerides; probably hormonal changes in female patients). $\mathrm{A}=\mathrm{D}$ with alexithymia seems partially linked with higher cholesterol, indicating neuroinflammation due to hypertriglycerides. In middle age cognitive damages can initiate due to many factors: alexithymia could be expression of their unhealthy state. It did not induce patients to body image alteration.

The features of the patients who perceived $\mathrm{A}<\mathrm{D}$ were: $89 \%$ did not use anti-hypertensive; $90 \%$ presented minimal depression; $50 \%$ were alexithymic and $34 \%$ presented probable alexithymia. Hypertension can influence alexithymia on $\mathrm{A}<\mathrm{D}$. The prevalence of probable alexithymia (38\%) was in patients who did not use anti-hypertensive medication (uncontrolled hypertension). It can be observed prevalence (86\%) of alexithymia among patients with controlled hypertension who used anti-hypertensive medication $(\mathrm{p}=0.069)$. This difference, not statically significant, indicated an aspect in $\mathrm{A}>\mathrm{D}$ : possible structural alteration.

$\mathrm{A}<\mathrm{D}$ can be resultant of patients with greater aware regarding their actual health state: $74 \%$ declared to be unsatisfied with their weight $(\mathrm{p}=0.068)$; $69 \%$ with their disease $(p=0.027)$. Youngest the patients, greater was their dissatisfaction with weight and disease.

A > D presented 3.6 more chances of moderate or severe depression (higher among males as already cited). Their depression here seems not accompanied by 
sentiments of fault, except in male who did not accept their appearance. Alexithymia, higher levels of depression (moderate or severe), higher levels of BMI (BMI III) seem importantly linked with $\mathrm{A}>\mathrm{D}$ as a type of weight misperception.

Females, who declared had been anteriorly made diet as treatment to lose weight were exactly those who perceived their weight A > D $(45 \%, \mathrm{p}=0.0091)$. Opposite attitude compared on male $\mathrm{A}>\mathrm{D}$.

Comparing on the patients who declared had been overweight during infancy one observed that $\mathrm{A}>\mathrm{D}$ (33\%) were different of those who perceived $A=D(18 \%)$ $(\mathrm{p}=0.073)$ and since adulthood $(\mathrm{p}=0.009)$ period in which $\mathrm{A}=\mathrm{D}$ was higher $(90 \%)$ than $\mathrm{A}>\mathrm{D}(73 \%)$, and $\mathrm{A}<\mathrm{D}$ (86\%). Even though not expressively, it can be observed that $\mathrm{A}=\mathrm{D}$ and $\mathrm{A}<\mathrm{D}$ were, in that case, more similar than $\mathrm{A}>\mathrm{D}$.

Higher was depression and alexithymia, crescent was the BMI. A > D seems expressing earlier beginning of obesity in life-course without diet, which explains more pro-inflammatory effects in psychological aspects and less diet during life. $\mathrm{A}<\mathrm{D}$ express anterior starting of overweight than $\mathrm{A}=\mathrm{D}$, but both made treatments against obesity "earlier" $(\mathrm{p}=0.0091)$.

If alexithymia is structural it partially explains less adherence to weight control and other items related to treatment. If associated to depression, it can be caused by pro-inflammation due to higher BMI (III) and their consequences. If it is an effect that did not contribute to the best comprehension of their won feelings and perception of weight, it can promote less adherence to diet and other treatments. If not structural, alexithymia seems an effect lack of model in general, beside lack of model to eating-control. It could also occur regarding feelings interpretation.

\section{Conclusions}

Age, gender and civil state, in this sequence, presented descending order, in relevance, for weight perception. Males with alexithymia and severe or moderate depression and anxiety, but also females, presented fewer tendencies to correctly perceive weight. $\mathrm{A}=\mathrm{D}$ presented lesser obesity during infancy and adolescence, explaining partially the lack of misperception between them.

Patients between 18 and 40 years old perceived with higher disapproving their weight, congruently with cultural and social demands of their life, but it seems with covert culpability among (or in) patients who "accepted" their appearance. Hypertension not treated could explain partially the alteration of perception achieved among them: $\mathrm{A}<\mathrm{D}$. The youngest the patient, the lesser was the actual BMI compared to the declared BMI; but younger was the patient, the greater their vulnerability to a pattern, contributing to this misperception.
It seems that the lower the acceptance of their own image the lower the admittance of reality, expressed by $\mathrm{A}>\mathrm{D}$, which seems present in patients with precocious beginning of overweight. A > D was linked with alexithymia, moderate or severe depression, BMI III and less diet anteriorly made during their lives if BMI III. Middle age or older were prevalent.

$\mathrm{A}<\mathrm{D}$ and $\mathrm{A}>\mathrm{D}$ were linked with higher presence of obesity during infancy and adolescence. $\mathrm{A}<\mathrm{D}$ (BMI I) seems associated with better self-control than $\mathrm{A}>\mathrm{D}$ (BMI III). A > D could be related to lack of model for self-control to eating, to interpret their feelings and body state, congruently with presence of alexithymia. Due to BMI III damages in satiety could be associated. Adolescence seems a crucial period in A > D.

Patients with Alexithymia who had $\mathrm{A}<\mathrm{D}$ were less prevalent than patients with Alexithymia with $\mathrm{A}=\mathrm{D}$ or $\mathrm{A}>\mathrm{D}$. Patients who perceived $\mathrm{A}=\mathrm{D}$ seems realistic regarding weight due to their "recent" discovered of obesity. A < D, among youngest patients, presented more aware about their state, expressing higher dissatisfaction with their weight, appearance and disease. Their overweight began earlier in age than $\mathrm{A}=\mathrm{D}$, but not $\mathrm{A}>\mathrm{D}$. The higher was the BMI, the higher the levels of anxiety, depression and alexithymia in this sample.

One limitation of the present study is the size of the sample. Limits of the laboratories to present results sooner regarding cholesterol, LDL, triglycerides, HDL, glycemia and glycolysed hemoglobin, available in reports ( 1 month before, or later, the tests and questionnaire applied).

\section{Abbreviations \\ $\mathrm{A}=\mathrm{D}$ : actual $\mathrm{BMI}=\operatorname{declared} \mathrm{BMl} ; \mathrm{A}>\mathrm{D}$ : actual $\mathrm{BMI}>$ declared $\mathrm{BMl} ; \mathrm{A}<\mathrm{D}$ : actual $\mathrm{BMI}<$ declared BMI.}

\section{Authors' contributions}

We declared that the research was conceived by MCOR. Both authors, in agreement, decided regarding the final design, instruments and procedure to collect the data. MCOR collected the data (with patients and in their reports), built the data set which allowed made the statical analysis. The statistical reports were made by Felipe Nascimento and mainly Cleide Aparecida Moreira Silva. The data analysis when necessary were discussed by both authors that agreed with the possible data interpretations. The article was written by MCOR and revised by MAT concerning their matter mainly when related to medical information. The english revision was made by Ana Carola Echelar Mohamed, Maria Emilia Rossi and Etna Macario in different phases in processing the article. The final form of article was discussed by both which in agreement submitted it to Diabetology \& Metabolic Syndrome. Both authors read and approved the final manuscript.

\section{Author details}

${ }^{1}$ Department of Human Being Development and Rehabilitation, Medical Faculty of State University of Campinas, Campinas, Brazil. ${ }^{2}$ Department of Internal Medicine, Endocrinology Metabolic Syndrome and Diabetes, Medical Faculty of State University of Campinas, Campinas, Brazil. 


\section{Acknowledgements}

Even though he doesn't belong to the area of the present research, the main acknowledgments necessarily is for Newton Luz Regina (in Memorian) whose life was completely dedicated to his family. He passed away during the article processing. His model of life and motivation to live were essential to conclude it.

Other important acknowledgment is for Sonia Muniz de Resende, psychoanalyst, and member of Unicamp, whose recommendations were essential to direct me to the present area, in which the research and article were made.

Ricardo Zollner, member of Unicamp, who believed in the project based on which the research was finally conceived. And Cleide Aparecida Moreira Silva whose statical analysis were essential to this research.

\section{Competing interests}

We declared there are not financial competing interests related to the authors of the present article: neither regarding to funding nor related to employment or personal financial interest.

We also declared there are not financial competing interests related to the present article: neither concerning to unpaid membership in a government or non-governmental organization or unpaid membership in an advocacy or lobbying organization nor related to unpaid advisory position in a commercial organization, writing or consulting for an educational company or acting as an expert witness.

\section{Consent for publication}

We declare our consent for publication of the manuscript entitled "Depression and alexithymia on weight perception in patients with metabolic syndrome and type 2 diabetes", which was revised by the Editorial of Diabetology \& Metabolic Syndrome accepted by the reviewer. We agree with the recommendations made by the reviewer.

We declare our agreement with the official terms prescribed by "Diabetology \& Metabolic Syndrome" for manuscript resulting from research, including all terms regarding our rights.

\section{Funding}

We declared that the present research not received subvention or any funding from elsewhere source, private or public.

\section{Publisher's Note}

Springer Nature remains neutral with regard to jurisdictional claims in published maps and institutional affiliations.

Received: 13 April 2016 Accepted: 2 April 2017

Published online: 12 May 2017

\section{References}

1. Lemon SC, Rosal MC, Zapka J, Bor A, Andersen V. Contributions of weight perceptions to weight loss attempts: differences by body mass index and gender. Body Image. 2009;6(2):90-6.

2. Jackson K, Janssen I, Appelhans B, Kazlauskaite R, Karavolos K, Dugan S, Avery E, Shipp-Johnson K, Powell L, Kravitz H. Body image satisfaction and depression in midlife women: the Study of Women's Health Across the Nation (SWAN). Arch Women's Mental Health. 2014;17(3):177-87.

3. Squiers L, Renaud J, McCromack L, Tzeng J, Bann C, Willinas P. How accurate are American's perception of their own weight? J Health Commun. 2014;19(7):795-812

4. Al Sabbah H, Vereecken CA, Elgar FJ, Nansel T, Aasvee K, Abdeen Z, Ojala K, Ahluwalia N, Maes L. Body weight dissatisfaction and communication with parents among adolescents in 24 countries: international crosssectional survey. BMC Public Health. 2009;9:52-62.

5. International Diabetes Federation; 2014. http://www.idf.org. Accessed March 2014.

6. Roberts C, Havener A, Barnard J. Metabolic syndrome and insulin resistance: underlying causes and modification by exercise training. Compr Physiol. 2013;3(1):1-58.
7. Gomes M, Giannella-Neto D, Faria M, Tambascia MA, Fonseca RN, Rea R, Macedo G, Modesto-Filho J, Schmid H, Bitterncourt A, Cavalcanti S, Rassi $\mathrm{N}$, Pedrosa H, Adib S. Estimating cardiovascular risk in patients with type 2 diabetes: a National Multicenter Study in Brazil. Diabetol Metab Syndr. 2009:1(1):22-6.

8. Tabák A, Herder C, Rathmann W, Brunner E, Kivimäki M. Prediabetes: a high-risk state for diabetes development. Lancet. 2012;379(9833):2279-90.

9. Keramati AR, Fathzadeh M, Go GW, Singh R, Choi M, Faramarzi S, Mane S, Kasaei M, Sarajzadeh-Fard K, Hwa J, Kidd KK, Bigi MB, Malezadeh R, Hosseinian A, Babaei M, Lifton R, Mani A. A form of the metabolic syndrome associated with mutations in DYRK1B. N Engl J Med. 2014;370(20):1909-19.

10. Lyra R, Cavalcanti N. Diabetes mellitus. 2nd ed; 2009. p. 117-24.

11. Techernof A, Després JP. Pathophysiology of human visceral obesity: an update. Pshysiol Rev. 2013;93(1):359-404.

12. Gregg EW, Li Y, Wang J, Burrows NR, Ali MK, Rolka D, Williams DE, Geiss L. Changes in diabetes-related complications in United States, 1990-2010. N Engl J Med. 2014;370(16):1514-23.

13. Barzilay Jl, Stein PK. Association of metabolic syndrome with age-related, nonatherosclerotic chronic medical conditions. Metab Syndr Relat Disord. 2011;9(5):327-35.

14. Mattila A. Alexithymia in finnish general population, academic dissertation. Tampere: Tampere University, Tampere School of Public Health; 2009.

15. Moriguchi Y, Komaki G. Neroimaging studies of alexithymia: physical, affective and social perspectives. Bio-psychosoc Med. 2013;7:8.

16. Kano M, Fukudo S. The Alexithymic brain: the neural pathways linking alexithymia to physical disorders. Biopsychosoc Med. 2013;7(1):2-9.

17. Karlsson H, Näätänen $\mathrm{P}$, Stenman H. Cortical Activation in Alexithymia as response to emotional stimuli. Br J Psychiatry. 2008;192:32-383.

18. Marchesi C, Brusamonti E, Maggini C. Are Alexithymia, depression and anxiety distinct constructs in affective disorders? J Psychosom Res. 2000:49(1):43-9.

19. Honkalampi K, Hintikka J, Tanskanen A, Lehtonen J, Viinamäki H. Depression is strongly associated with Alexithymia in the general population. J Psychosom Res. 2000;48:99-104.

20. Honkalampi K, Hintikka J, Saarinen P, Lehtonen J. Is Alexithymia a permanent feature in depressed patients? Results from a 6-month follow-up study. Psychother Psychosom. 2000;69:303-8.

21. Honkalampi K, Hintikka J, Laukkanen E, Lehtonen J, Viinamäki H. Alexithymia and depression. A prospective study of patients with major depressive disorder. Psychosomatics. 2001;43(3):229-34.

22. Honkalampi K, Koivumaa-Honkanen H, Hintikka J, Antikainen R, Haatinen K, Tanskanen A, Viinamäki H. Do stressful life-events or sociodemographic variables associate with depression and Alexithymia among a general population? A 3-year follow-up study comprehensive psychiatry. Am J Psychiatr. 2002;159:961-7

23. Kano M, Fukudo S, Gyoba J, Kamachi M, Tagawa M, Mochizuki H, Itoh M, Hongo M, Yanai K. Specific brain processing of facial expressions in people with Alexithymia: an H2 150-Pet Study. Brain. 2003;126(6):1474-84.

24. Meltzer M, Kristy N. Memory for emotionally provocative words in Alexithymia: a role for stimulus relevance. Conscious Cogn. 2010;19(4):1062.

25. Moriguchi Y, Ohnisi T, Lane RD, Maeda M, Mori T, Nemoto K, Matsuda H, Komaki G. Impaired self-awareness and theory of mind: an fMRI study of mentalizing in Alexithymia. Neuroimage. 2006;32(3):1472-82.

26. Lumley MA, Neely LC, Burger AJ. The assessment of Alexithymia in medical settings: implications for understanding and treating health problems J Pers Assess. 2007;89(3):230-46.

27. Liemburg EJ, Stwart M, Bruggermn R, Korte Kaas R, Curcic'-Blake B, Aleman A. Altered resting state connectivity of the default mode network in Alexithymia. Soc Cogn Affect Neurosci. 2012;7(6):660-6.

28. Pollatos O, Gramann K. Eletrophysiological evidence of early processing deficits in Alexithyma. Biol Psychol. 2011;87(1):113-21.

29. Moriguchi Y, Decet J, Maeda M, Mori T, Matsuda H, Komaki G. Empathy and judging other's pain: an fMRI study of Alexithymia. Cereb Cortex. 2007:17(9):2223-34.

30. Berthoz S, Artiges E, Moortele PF, Poline JB, Rouquette S, Consoli S, Martinot JL. Effect of Impaired recognition and expression of emotions on frontocingulate cortices: an fMRI study of men with Alexithymia. Am J Psychiatr. 2002;159:961-7. 
31. Bremmer MA, Beekman ATF, Deeg DJH, Pennix BWJH, Dik MG, Hack CE, Hoogendijik WJG. Inflammatory markers in late-life depression: results from a population-based study. J Affect Disord. 2007.

32. Soczynska JK, Kennedy SH, Woldeyohannes HO, Liauw SS, Alsuwaidan M, Yim CY, Mclntrye RS. Mood disorders and obesity: understanding inflammation as a pathophysiological nexus. Neuromol Med. 2011;13(2):93.

33. Anisman H. Inflaming depression. J Psychiatry Neurosci. 2011;36(5):291-5.

34. Dantzer R, O'Connor JC, Lawson M, Kelley KW. Inflammation-associated depression: from serotonin to kynurenine. Psychoneuroendocrinology. 2011;36(3):426-36.

35. Tabák A, Akbraly TN, Batty GD, Kivimaki M. Depression and type 2 diabetes: a causal association? Lancet Diabetes Endocrinol. 2014;2(3):236-45.

36. Tuligenga RH, Dugravot A, Tabák AG, Elbaz A, Brunner EJ, Kivimák M, Singh-Manoux A. Midlife type 2 diabetes and poor glycaemic control as risk factors for cognitive decline in early old age: a Post-hoc analysis of the whitehall II cohort study. Lancet Diabetes Endocrinol. 2013;2(3):228-35.
37. World Health Organization. Geneva: World Health Organisation. http:// www.who.int/mediacentre/factsheets/fs311/en/.

38. Lloyd CE, Roy T, Nouwen A, Chauran AM. Epidemiology of depression in diabetes: international and cross-cultural issues. J Affect Disord. 2012;14251:522-9.

39. Xu W, Goldberg SI, Shubina M. A Turchin Optimal systolic blood pressure target, time to intensification, and time to follow-up in treatment of hypertension: population based retrospective cohort study. Br Med J. 2015;5:350-9.

40. Li L, Hardy R, Kuh D, Power C. Life-course body mass index trajectories and blood pressure in mid life in two British birth cohorts: stronger associations in the later-born generation. Int J Epidemiol. 2015;2:1-9.

41. Mcphee SJ, Papadakis MA. Current medical Diagnosis \& Treatment. Systemic hypertension. 2012;11:421-49.

\section{Submit your next manuscript to BioMed Central and we will help you at every step:}

- We accept pre-submission inquiries

- Our selector tool helps you to find the most relevant journal

- We provide round the clock customer support

- Convenient online submission

- Thorough peer review

- Inclusion in PubMed and all major indexing services

- Maximum visibility for your research

Submit your manuscript at www.biomedcentral com/submit 